\title{
Hypofractionated radiotherapy after conservative surgery may increase low-intermediate grade late fibrosis in breast cancer patients
}

This article was published in the following Dove Press journal: Breast Cancer - Targets and Therapy

\section{Cinzia Digesù,' Francesco \\ Deodato,' Gabriella \\ Macchia,' Savino Cilla, ${ }^{2}$ \\ Martina Pieri, ${ }^{3}$ Alice \\ Zamagni, ${ }^{4}$ Andrea Farioli, ${ }^{5}$ \\ Milly Buwenge, ${ }^{4}$ Gabriella \\ Ferrandina, ${ }^{6, *}$ Alessio $\mathrm{G}$ \\ Morganti, $4, *$}

'Radiotherapy Unit, General Oncology Unit, Fondazione Giovanni Paolo II, Campobasso, Italy; ${ }^{2}$ Medical Physics Unit, Fondazione Giovanni Paolo II, Campobasso, Italy; ${ }^{3}$ Radiotherapy Unit, Istituto Scientifico Romagnolo per lo Studio e la Cura dei Tumori, Meldola, Italy; ${ }^{4}$ Radiation Oncology Center, Department of Experimental, Diagnostic and Specialty Medicine, University of Bologna, Bologna, Italy; ${ }^{5}$ Department of Medical and Surgical Sciences, University of Bologna, Bologna, Italy; ${ }^{6}$ Department of Woman and Child Health, Gynecologic Oncology Unit, Fondazione "Policlinico Universitario A. Gemelli", IRCSS, Universita' Cattolica Sacro Cuore, Rome, Italy

*These authors contributed equally to this work

Correspondence: Gabriella Macchia Radiotherapy Unit, General Oncology Unit, Fondazione Giovanni Paolo II, Università Cattolica del Sacro Cuore, Largo A Gemelli I, 86100 Campobasso, Italy

Tel +39 05। 2143564

Fax +3905I 6364336

Email rt.unibo@gmail.com
Aim: To compare late toxicity after postoperative hypofractionated radiotherapy (RT) and standard fractionated RT in patients with early-stage breast carcinoma.

Methods: This retrospective study included 447 patients (Modulated Accelerated Radiotherapy [MARA-1]: 317 patients, and control group [CG]: 130 patients). In the CG, the whole breast received 50.4 Gy in 28 fractions ( $\mathrm{fx}$ ) using 3D-radiotherapy, plus a sequential electron boost ( $10 \mathrm{~Gy}$ in $4 \mathrm{fx}$ ) to tumor bed. In MARA-1 group, a forward-planned intensity-modulated radiotherapy technique with $40 \mathrm{~Gy}$ in $16 \mathrm{fx}$ with a concomitant boost of 4 Gy to breast was used. The primary endpoint was to evaluate late toxicity, and secondary endpoints were acute toxicity, local control, and survival. ClinicalTrials.gov: NCT03461224.

Results: Median follow-up was 52 months (range: 3-115 months). Late skin and subcutaneous toxicity were acceptable: 5-year actuarial cumulative incidence of Grade (G) 3 late skin toxicity was $1.5 \%$ in CG and $0.0 \%$ in MARA-1. Five-year actuarial cumulative incidence of G3 late subcutaneous toxicity was $0.8 \%$ in CG and $0.3 \%$ in MARA-1. On multivariate analysis, tobacco smoking and planning target volume were associated with an increased risk of late $\mathrm{G} 1$ skin toxicity (HR: 2.15, 95\% CI: $1.38-3.34$ and HR: 1.12, 95\% CI: $1.07-1.18$, respectively), whereas patients with a larger planning target volume also showed an increased risk of G1 and G2 late subcutaneous toxicity (HR: 1.14, CI 95\%: 1.08-1.20 and HR: 1.14, 95\% CI: 1.01-1.28, respectively). MARA-1 patients also showed an increased risk of late G1 and G2 subcutaneous toxicity (HR: $2.35,95 \%$ CI: $1.61-3.41$ and HR: $3.07,95 \%$ CI: $1.11-8.53$, respectively) compared to $\mathrm{CG}$.

Conclusion: In this retrospective analysis, postoperative accelerated-hypofractionated RT for early-stage-breast carcinoma was associated with higher incidence of subcutaneous side effects. However, this increase was limited to G1-G2 toxicity. In the future, development of predictive models could help in tailoring dose and fractionation based on the risk of toxicity.

Keywords: breast cancer, radiotherapy, hypofractionation, retrospective study

\section{Introduction}

Radiotherapy (RT) after surgery is a standard component of breast conserving therapy (BCT) for invasive breast cancer (BC). RT reduces the risk of local and regional recurrences and improves overall survival. ${ }^{1,2}$ Historically, the standard dose after breast conservative surgery was $50 \mathrm{~Gy}$, delivered in 25 fractions (fx) of $2 \mathrm{~Gy}$, with or without a boost to the tumor bed. ${ }^{3}$

With an improved understanding of $\alpha / \beta$ ratio of $\mathrm{BC}$, accelerated-hypofractionated (AHF) regimens have been proposed. Available clinical data suggest an intermediate $\alpha / \beta$ ratio for $B C$, lower than that of other tumors and early-reacting tissues; thus, a 
clinical advantage from AHF regimens should be expected. ${ }^{4}$ Furthermore, AHF-RT may limit the engagement of patients and RT departments with discomfort and cost reduction. ${ }^{5}$ However, the use of AHF may theoretically result in increased late toxicity with worsened cosmetic results. ${ }^{6}$

Improvement of local control (LC) and OS in early-stage $\mathrm{BC}$ are the most common benefits of postoperative RT, and studies have demonstrated the noninferiority of AHF wholebreast irradiation as compared to conventionally fractionated whole-breast-irradiation. ${ }^{7-9}$ In 2011, the American Society for Radiation Oncology published consensus recommendations for the use of hypofractionated whole breast (HF-WB). ${ }^{10}$ Another study about acute toxic effects demonstrated significantly reduced higher maximum physician-assessed skin reaction, self-reported pain, and fatigue. ${ }^{11}$

Despite available evidence, the use of AHF schedules is still debated due to pending questions such as the optimal AHF treatment schedule, tolerability in high-risk patients requiring chemotherapy or regional nodes irradiation, cardiac toxicity in patients with left-sided tumor, and efficacy in patients with ductal carcinoma in situ.

The aim of this study was to evaluate the clinical results in terms of late skin and subcutaneous toxicity of AHF forwardplanned intensity-modulated radiotherapy (IMRT) in patients with early-stage BC. Results were compared with a historical control group (CG) of patients treated with 3D-conformal postoperative RT delivered with conventional fractionation, before the introduction of AHF treatments in this setting in our department.

\section{Materials and methods Study design}

This trial was a retrospective study on postoperative AHF IMRT (MARA-1). Preliminary positive results in terms of acute toxicity were previously published on a group of 99 patients. ${ }^{12}$ From that analysis and the evidence coming from randomized trials, ${ }^{8,9}$ the MARA-1 schedule became our institutional standard protocol for postoperative RT in low-risk early-stage BC.

\section{Endpoints}

The primary endpoint was to evaluate late (cutaneous and subcutaneous) toxicity. Secondary endpoints were acute toxicity, LC, and survival.

\section{Eligibility}

Patients at low risk of recurrence were eligible for the study. Inclusion criteria were as follows: confirmed histologic evidence of early-stage BC who underwent BCT, postmenopausal (at least 3 years) status, and patients with clear surgical margins ( $>3 \mathrm{~mm}$ ). Exclusion criteria were pT4 pathologic stage, positive or close resection margins, $\geq 3$ metastatic axillary nodes, nodal irradiation, and distant metastasis.

\section{Treatment planning}

All patients had computed tomography scans for treatment planning. An alpha cradle immobilization device was used for patient treatment reproducibility. The clinical target volume 1 (CTV1) delineation included the tumor bed, while the clinical target volume 2 (CTV2) was the entire WB tissue with the exclusion of the skin $(5 \mathrm{~mm})$. The planning target volumes (PTV1 and PTV2) were defined as CTV1 and CTV2 plus an isotropic $8 \mathrm{~mm}$ margin excluding the skin surface. In the CG patients, the WB tissue was irradiated by two conformed tangential beams with standard multileaf collimators and wedge filters while the tumor bed (boost) was irradiated by a direct electron beam. The dose was prescribed according to the ICRU 62 report. In the MARA-1 patients, the treatment planning optimization was obtained using a forwardplanned IMRT technique, as previously described. ${ }^{12}$ This is a simplified form of IMRT, in which the contribution from each tangential beam was divided into two different segments. One segment was designed to include the WB using $6 \mathrm{MV}$ photon beams. This configuration, in the absence of filters, results in a volume of underdosage in the thickest region of the breast. From this resulting inhomogeneous dose distribution, the second segment, usually with $15 \mathrm{MV}$ photon energy, was conformed to block the dose $>107 \%$ and directed to the areas of underdosage in order to increase the dose to the deepest part of the breast while sparing the most superficial part (Figure 1).

\section{Treatment}

In CG patients, the residual breast (PTV2) was irradiated with a dose of 50.4 Gy in 28 daily fx and the PTV1 with a sequential boost of $10 \mathrm{~Gy}$ in $4 \mathrm{fx}$. In MARA-1 patients, PTV2 was irradiated with a total dose of $40 \mathrm{~Gy}$ in $16 \mathrm{fx}$ with a concomitant 3D-RT boost of $4 \mathrm{~Gy}$ in $0.25 \mathrm{~Gy} / \mathrm{fx}$. RT was performed after at least 3 weeks from the end of systemic treatments in patients undergoing adjuvant chemotherapy. Toxicity was assessed in both groups, using the same timing. Patient's clinical examinations were performed at least once a week during RT. All patients applied Biafin cream (Janssen-Cilag AG, Zug, Switzerland) at least once a day on the irradiated skin, and in case of Grade 2 toxicity supportive therapy with topical steroids was given. 


\section{Follow-up}

All patients underwent clinical examinations every 6 months and bilateral mammography every 12 months. Late toxicity was graded using Radiation Therapy Oncology Group/ European Organization for Research and Treatment Cancer (RTOG/EORTC) criteria $^{13}$ in both groups of patients (Table 1) and was assessed every 6 months for the first 2 years and annually thereafter. Information on possible predictors of late toxicity was collected at the first medical examination.

\section{Statistical analysis}

Ten patients with missing information on PTV volume ( $\mathrm{n}=8)$ or diabetes $(\mathrm{n}=2)$ were excluded from the main analysis (list wise deletion). In the descriptive tables, summary statistics were expressed as numbers (percentages) or medians (interquartile range). Survival curves were plotted using the Kaplan-Meier method and compared through log-rank test. We fit Cox proportional-hazards regression models to estimate HR of Grade 1 and 2 skin and subcutaneous toxicity and $95 \%$ CIs using time since diagnosis as the main temporal axis. HRs of Grade 3 late skin and subcutaneous toxicity

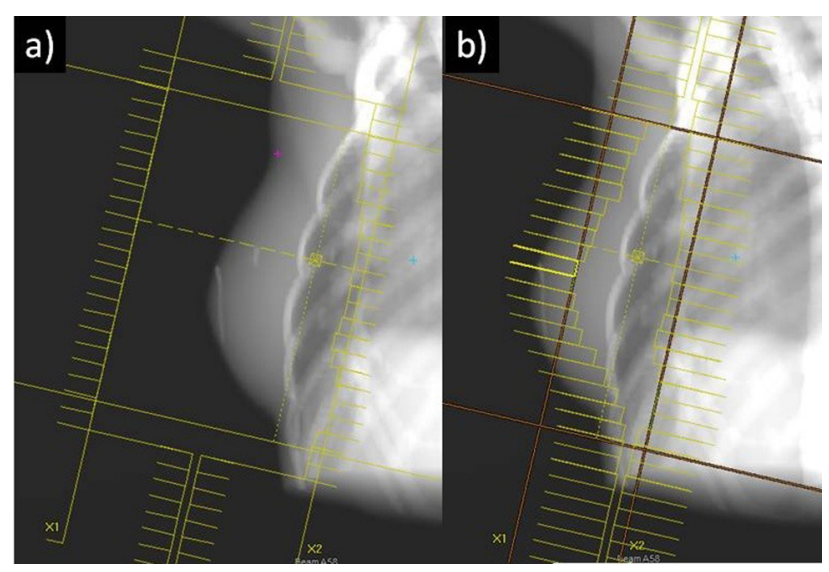

Figure I Example of the used IMRT technique (forward-planned).

Notes: The two tangential beams were divided into two different segments: one segment (A) was designed to include the WB without filters (6 MV photons) and a second segment (B) was directed to the area of under dosage to compensate for dose loss (I5 MV photons).

Abbreviations: IMRT, intensity-modulated radiotherapy; WB, whole breast. were not estimated due to the limited number of events (two for each outcome). Covariates to be introduced in the multivariable models were selected based on backward stepwise strategy ( $P$ inclusion $<0.1 ; P$ exclusion $\geq 0.1$ ). A possible nonlinear association between PTV volume and the risk of late skin and subcutaneous toxicity was explored using natural cubic splines, but no evidence of nonlinear relationship was observed. Therefore, PTV volume was included in the models as a continuous variable with one degree of freedom. Statistical analyses were performed using Stata 12.1 SE (Stata Corp, College Station, TX, USA). We defined as statistically significant a two-sided $P$-value $<0.05$. The statistical significance in the actuarial analyses was evaluated considering the outcomes as continuous variables and not as a specific time point.

\section{Ethical issues}

All patients signed a written informed consent to treatment. The study was approved by the institutional review board of the Catholic University. The study is registered in an international public registry (ClinicalTrials.gov: NCT03461224).

\section{Results}

Four hundred and forty-seven patients were included in this analysis: MARA-1 (317) and CG (130). The median follow-up was 52 months (range: $3-115$ ). In Table 2 patient characteristics and in Table 3 treatment characteristics are shown, respectively. Five patients $(1.1 \%)$ had local or regional relapses: 4 (3.1\%) in CG and 1 (0.3\%) in MARA-1 group. Five-year LC was $96.7 \%$ and $100 \%$ in CG and MARA-1 groups, respectively $(P=0.02)$.

Late skin and subcutaneous toxicity were acceptable: 5 -year G1 skin late toxicity-free survival (LTFS) was $61.1 \%$ in CG and $56.1 \%$ in MARA-1 ( $P$ : NS) while G2 skin LTFS was $93.3 \%$ in CG and $92.9 \%$ in MARA-1 ( $P$ : NS), respectively (Table 4; Figures 2 and 3). G3 skin LTFS was 98.2\% in CG while no G3 toxicity was observed in MARA-1 ( $P$ : NS) (Table 4). On multivariate analysis, tobacco smoking and larger PTV2 volume were significantly associated with

Table I RTOG/EORTC scale for late toxicity

\begin{tabular}{|c|c|c|c|c|}
\hline Organ tissue & Grade I & Grade 2 & Grade 3 & Grade 4 \\
\hline Skin & $\begin{array}{l}\text { Slight atrophy; pigmentation } \\
\text { change; some hair loss }\end{array}$ & $\begin{array}{l}\text { Patch atrophy; moderate } \\
\text { telangiectasia; total hair loss }\end{array}$ & Marked atrophy; gross telangiectasia & Ulceration \\
\hline $\begin{array}{l}\text { Subcutaneous } \\
\text { tissue }\end{array}$ & $\begin{array}{l}\text { Slight induration (fibrosis) and } \\
\text { loss of subcutaneous fat }\end{array}$ & $\begin{array}{l}\text { Moderate fibrosis but asymptomatic; } \\
\text { slight field contracture }<10 \% \text { linear } \\
\text { reduction }\end{array}$ & $\begin{array}{l}\text { Severe induration and loss of } \\
\text { subcutaneous tissue; field contracture } \\
>10 \% \text { linear measurement }\end{array}$ & Necrosis \\
\hline
\end{tabular}

Abbreviation: RTOG/EORTC, Radiation Therapy Oncology Group/European Organization for Research and Treatment Cancer. 
Table 2 Patients' characteristics

\begin{tabular}{|c|c|c|c|}
\hline \multirow[t]{2}{*}{ Characteristics } & \multicolumn{2}{|l|}{ Fractionation schedule } & \multirow[t]{2}{*}{ Total, $N=447$} \\
\hline & 50.4 Gray in $28 \mathrm{fx}, \mathrm{N}=130$ & $40 \mathrm{~Gy}$ in $16 \mathrm{fx}, \mathrm{N}=317$ & \\
\hline Average age, median (IQR) & $55(46-65)$ & $65(60-7 I)$ & $63(56-70)$ \\
\hline \multicolumn{4}{|l|}{ Cancer site, N (\%) } \\
\hline Right & $61(46.9)$ & $146(46.1)$ & $207(46.3)$ \\
\hline Left & $69(53.1)$ & I7I (53.9) & $240(53.7)$ \\
\hline \multicolumn{4}{|l|}{ Histologic type, N (\%) } \\
\hline Invasive ductal & $75(57.7)$ & $201(63.4)$ & $276(61.7)$ \\
\hline Invasive lobular & $14(10.7)$ & $39(12.3)$ & $53($ (II.9) \\
\hline Mixed & $21(16.2)$ & 37 (II.7) & $58(13.0)$ \\
\hline Ductal in situ & $10(7.7)$ & $17(5.4)$ & $27(6.0)$ \\
\hline Lobular in situ & $0(0)$ & $\mathrm{I}(0.3)$ & $I(0.2)$ \\
\hline Other & $10(7.7)$ & $22(6.9)$ & $32(7.2)$ \\
\hline \multicolumn{4}{|l|}{ T stage, $\mathrm{N}(\%)$} \\
\hline TI & 77 (59.2) & $235(74.1)$ & $312(69.8)$ \\
\hline $\mathrm{T} 2$ & $4 \mid(3 I .6)$ & $67(21.1)$ & $108(24.2)$ \\
\hline T3 & $3(2.3)$ & $2(0.6)$ & $5(1.1)$ \\
\hline $\mathrm{T} 4$ & $4(3.1)$ & $0(0.0)$ & $4(0.9)$ \\
\hline Not known & $5(3.8)$ & $13(4.2)$ & $18(4.0)$ \\
\hline \multicolumn{4}{|l|}{ Tumor grade, $N(\%)$} \\
\hline I & $19(14.6)$ & $73(23.0)$ & $92(20.6)$ \\
\hline 2 & $59(45.4)$ & $162(51.1)$ & $221(49.4)$ \\
\hline 3 & $48(36.9)$ & $76(24.0)$ & $124(27.7)$ \\
\hline Not known & $4(3.1)$ & $6(1.9)$ & $10(2.3)$ \\
\hline \multicolumn{4}{|c|}{ Pathological nodal status, N (\%) } \\
\hline Positive & $4 \mid(3 \mid .6)$ & $53(16.7)$ & $94(21.0)$ \\
\hline Negative & $89(68.4)$ & $264(83.3)$ & $353(79.0)$ \\
\hline Not known & $0(0.0)$ & $0(0.0)$ & $0(0.0)$ \\
\hline
\end{tabular}

Abbreviations: $\mathrm{fx}$, fractions; IQR, interquartile range; $\mathrm{N}$, number of patients.

Table 3 Treatment characteristics

\begin{tabular}{|c|c|c|c|}
\hline \multirow[t]{2}{*}{ Characteristics } & \multicolumn{2}{|l|}{ Fractionation schedule } & \multirow[t]{2}{*}{ Total, $\mathrm{N}=447$} \\
\hline & $50.4 \mathrm{~Gy}$ in $28 \mathrm{fx}, \mathrm{N}=130$ & $40 \mathrm{~Gy}$ in $16 \mathrm{fx}, N=317$ & \\
\hline \multicolumn{4}{|l|}{ Regional node irradiation, N (\%) } \\
\hline No & $109(83.8)$ & $317(100)$ & $42(95.3)$ \\
\hline Yes & $21(16.2)$ & $0(0)$ & $21(4.7)$ \\
\hline \multicolumn{4}{|l|}{ Adjuvant chemotherapy, N (\%) } \\
\hline No & $46(35.4)$ & $212(66.9)$ & $258(57.7)$ \\
\hline Yes & $84(64.6)$ & $105(33.1)$ & $189(42.3)$ \\
\hline \multicolumn{4}{|l|}{ Chemotherapy schedule, N (\%) } \\
\hline No & $45(34.6)$ & $213(67.1)$ & $258(57.7)$ \\
\hline CMF & $28(2 \mid .6)$ & $23(7.3)$ & $51(11.4)$ \\
\hline Anthracycline & $55(42.3)$ & $69(21.8)$ & $124(27.7)$ \\
\hline Anthracycline + docetaxel & $2(1.5)$ & $12(3.8)$ & $14(3.2)$ \\
\hline \multicolumn{4}{|c|}{ Adjuvant hormonotherapy, N (\%) } \\
\hline No & $46(35.4)$ & $34(10.7)$ & $80(17.9)$ \\
\hline Yes & $84(64.6)$ & $283(89.3)$ & $367(82.1)$ \\
\hline
\end{tabular}

Abbreviations: CMF, cyclophosphamide, methotrexate, and 5-fluorouracil; fx, fractions; N, number of patients.

an increased risk of late G1 skin toxicity, whereas only larger PTV volume was significantly associated with G2 late skin toxicity (Table 5). G1 subcutaneous LTFS was $73.4 \%$ and $49.1 \%$ in CG group and MARA-1 $(P<0.001)$, respectively, and G2 subcutaneous LTFS was $96.5 \%$ in CG group and
89.6\% in MARA-1 ( $P: 0.03$ ), respectively (Table 6). Multivariate analysis confirmed that late subcutaneous toxicity was significantly associated with RT modality (Table 7). The use of the AHF regimen increased the risk of late G1 and G2 toxicity (HR 2.35, 95\% CI: 1.61-3.41 and HR 3.07, 
Table 4 Univariate analysis of late skin toxicity

\begin{tabular}{|c|c|c|c|c|c|c|}
\hline \multirow[t]{2}{*}{ Variable } & \multicolumn{6}{|c|}{ 5-year late skin toxicity-free survival } \\
\hline & GI & $\boldsymbol{P}$ & G2 & $\boldsymbol{P}$ & G3 & $\boldsymbol{P}$ \\
\hline \multicolumn{7}{|l|}{ Technique } \\
\hline CG & 61.1 & 0.49 & 93.3 & 0.99 & 98.2 & 0.16 \\
\hline MARA-I & 56.1 & & 92.9 & & 100 & \\
\hline \multicolumn{7}{|c|}{ Hypertension } \\
\hline No & 54.7 & 0.20 & 93.5 & 0.60 & 100 & 0.07 \\
\hline Yes & 64.3 & & 92.7 & & 97.7 & \\
\hline \multicolumn{7}{|l|}{ Diabetes } \\
\hline No & 54.7 & 0.16 & 93.5 & 0.69 & 100 & 0.74 \\
\hline Yes & 64.3 & & 92.7 & & 97.7 & \\
\hline \multicolumn{7}{|c|}{ Tobacco smoking } \\
\hline No & 60.4 & 0.007 & 93.1 & 0.95 & 99 & 0.64 \\
\hline Yes & 43.4 & & 93.7 & & 100 & \\
\hline \multicolumn{7}{|l|}{ Alcohol } \\
\hline No & 56.8 & 0.22 & 92.1 & 0.16 & 98.8 & 0.40 \\
\hline Yes & 61.6 & & 95.6 & & 100 & \\
\hline \multicolumn{7}{|c|}{ Chemotherapy } \\
\hline No & 60.0 & 0.77 & 93.5 & 0.72 & 100 & 0.17 \\
\hline Yes & 57.2 & & 92.6 & & 98.3 & \\
\hline \multicolumn{7}{|c|}{ Hormone therapy } \\
\hline No & 59.2 & 0.98 & 95 & 0.45 & 100 & 0.41 \\
\hline Yes & 58.1 & & 92.8 & & 98.8 & \\
\hline \multicolumn{7}{|l|}{ PTV volume } \\
\hline 1 & 64.4 & 0.002 & 98.5 & $<0.001$ & 100 & 0.21 \\
\hline 2 & 55.3 & & 90.4 & & 97.7 & \\
\hline 3 & 36.1 & & 74.7 & & 100 & \\
\hline
\end{tabular}

Abbreviations: CG, control group; G, grade; MARA-I, Modulated Accelerated Radiotherapy; PTV, planning target volume.

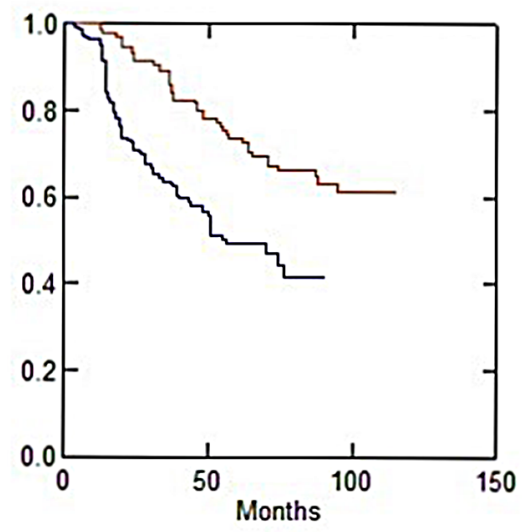

Figure 2 Actuarial grade I late subcutaneous toxicity-free survival vs treatment technique.

Notes: The y axis indicates survival probability; the red colour shows the control group curve; the blue colour shows the MARA-I curve.

$95 \%$ CI: $1.11-8.53$, respectively). Furthermore, patients with a larger PTV presented an increased risk of G1 and G2 late subcutaneous toxicity. Moreover, diabetes was associated with increased G1 late subcutaneous toxicity (Table 7). G3 late LTFS were $99.2 \%$ in CG and $99.6 \%$ in MARA-1 ( $P$ : NS), respectively.

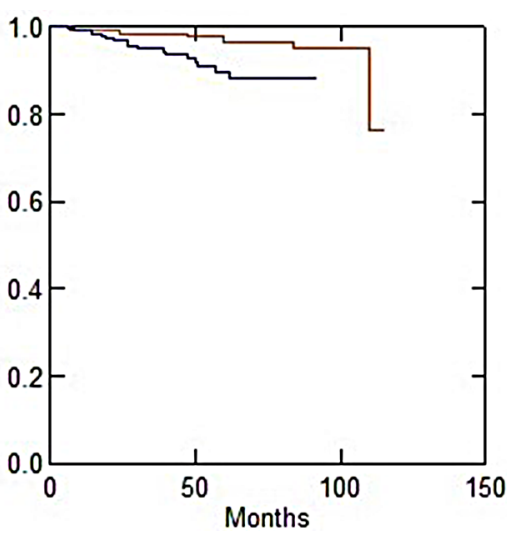

Figure 3 Actuarial grade 2 late subcutaneous toxicity-free survival vs treatment technique.

Notes: The $y$ axis indicates survival probability; the red colour shows the control group curve; the blue colour shows the MARA-I curve.

\section{Discussion}

We started this trial was in 2003 to evaluate late toxicity using an AHF regimen prior to the publication of several randomized studies. ${ }^{8,9,14}$ To reduce the potential risk of increased toxicity, we opted for the use of IMRT technique. Our study reported a significant difference between AHF and conventional 3D-technique with higher rates of G1-G2 late subcutaneous toxicity after AHF and no differences between the two techniques in terms of late skin toxicity. A relevant limitation of our study is the lack of evaluation of cosmesis and patient-reported outcome measures. However, regarding the higher incidence of mild-moderate fibrosis in patients who underwent the MARA-1 protocol, in our opinion the impact was modest if not entirely irrelevant from the patient's point of view. However, we must admit that our study had a retrospective design and the comparisons were made on a previously treated CG. Moreover, the results of our analysis are potentially affected by bias and cannot be considered as "high level of evidence."

The 10-year results from START-A and START-B trials and from the Ontario Clinical Oncology Group trial did not show a higher toxicity after AHF in women undergoing BCT for early-stage invasive $\mathrm{BC}$ with clear surgical margins and negative axillary nodes. ${ }^{8,9}$

The UK randomized trials compared the standard fractionation 50 Gy in $25 \mathrm{fx}$ with three schemes of HF-RT: 39 or 41.6 Gy in $13 \mathrm{fx}$ over 5 weeks and 40 Gy in $15 \mathrm{fx}$ over 3 weeks. In both trials a boost of $10 \mathrm{~Gy}$ in $5 \mathrm{fx}$ was delivered after initial RT in a variable percentage of patients. In that study a nonsignificantly higher rate of breast induration and telangiectasia was recorded in the 41.6 Gy AHF group. ${ }^{8}$ The authors reported a 10 -year good to excellent cosmetic 
Table 5 HRs of GI and G2 late skin toxicity estimates from Cox proportional-hazards regression models

\begin{tabular}{|c|c|c|c|c|c|c|c|c|}
\hline \multirow[t]{2}{*}{ Variable } & \multirow[t]{2}{*}{ Value } & \multirow{2}{*}{$\begin{array}{l}\text { Late skin } \\
\text { toxicity }\end{array}$} & \multicolumn{3}{|c|}{ Univariate analysis $^{\mathbf{a}}$} & \multicolumn{3}{|c|}{ Multivariate analysis $^{\mathbf{a}}$} \\
\hline & & & HR & $(95 \% \mathrm{Cl})$ & $\boldsymbol{P}$ & HR & $(95 \% \mathrm{CI})$ & $P$ \\
\hline \multirow[t]{2}{*}{ Technique } & MARA-I & GI & 1.07 & $(0.77-1.50)$ & 0.686 & & & \\
\hline & & G2 & 1.31 & $(0.54-3.17)$ & 0.555 & & & \\
\hline \multirow[t]{2}{*}{ Hypertension } & & GI & 0.80 & $(0.58-1.12)$ & 0.191 & & & \\
\hline & & $\mathrm{G} 2$ & 1.03 & $(0.44-2.42)$ & 0.939 & & & \\
\hline \multirow[t]{2}{*}{ Diabetes } & & GI & 1.43 & $(0.85-2.39)$ & 0.179 & & & \\
\hline & & G2 & 1.22 & $(0.29-5.23)$ & 0.788 & & & \\
\hline \multirow[t]{2}{*}{ Tobacco smoking } & & GI & 1.88 & $(1.22-2.91)$ & 0.005 & 2.15 & $(1.38-3.34)$ & 0.001 \\
\hline & & $\mathrm{G} 2$ & 0.88 & $(0.2 \mathrm{I}-3.79)$ & 0.869 & & & \\
\hline \multirow[t]{2}{*}{ Alcohol } & & GI & 0.77 & $(0.53-1.11)$ & 0.156 & & & \\
\hline & & $\mathrm{G} 2$ & 0.38 & $(0.11-1.28)$ & 0.117 & & & \\
\hline \multirow[t]{2}{*}{ Chemotherapy } & & GI & 0.95 & $(0.69-1.30)$ & 0.734 & & & \\
\hline & & G2 & 1.34 & $(0.58-3.12)$ & 0.497 & & & \\
\hline \multirow[t]{2}{*}{ Hormone therapy } & & GI & 0.85 & $(0.58-1.24)$ & 0.399 & & & \\
\hline & & $\mathrm{G} 2$ & 1.81 & $(0.53-6.13)$ & 0.342 & & & \\
\hline \multirow[t]{2}{*}{ PTV volume } & & GI & 1.11 & $(1.06-1.17)$ & 0.001 & 1.12 & $(1.07-1.18)$ & 0.001 \\
\hline & & G2 & 1.27 & $(I .15-I .4 I)$ & 0.001 & 1.27 & $(I .15-I .4 I)$ & 0.001 \\
\hline
\end{tabular}

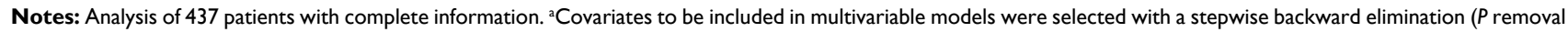
$=0.10$; $P$ addition $<0.10$ ) based on likelihood ratio test.

Abbreviations: G, grade; $P$, probability; MARA-I, Modulated Accelerated Radiotherapy.

Table 6 Univariate analysis of late subcutaneous toxicity

\begin{tabular}{|c|c|c|c|c|c|c|}
\hline \multirow[t]{2}{*}{ Variable } & \multicolumn{6}{|c|}{$\begin{array}{l}\text { 5-year late subcutaneous toxicity-free } \\
\text { survival }\end{array}$} \\
\hline & GI & $P$ & G2 & $P$ & G3 & $P$ \\
\hline \multicolumn{7}{|l|}{ Technique } \\
\hline CG & 73.4 & $<0.001$ & 96.5 & 0.03 & 99.2 & 0.67 \\
\hline MARA-I & 49.1 & & 89.6 & & 99.6 & \\
\hline \multicolumn{7}{|c|}{ Hypertension } \\
\hline No & 57 & 0.41 & 92.6 & 0.91 & 99.1 & 0.25 \\
\hline Yes & 59.7 & & 92.3 & & 100 & \\
\hline \multicolumn{7}{|l|}{ Diabetes } \\
\hline No & 59.7 & 0.02 & 93.8 & 0.05 & 99.4 & 0.68 \\
\hline Yes & 31.5 & & 82.2 & & 100 & \\
\hline \multicolumn{7}{|c|}{ Tobacco smoking } \\
\hline No & 57.3 & 0.50 & 92.8 & 0.23 & 99.7 & 0.07 \\
\hline Yes & 65.7 & & 90 & & 96.8 & \\
\hline \multicolumn{7}{|l|}{ Alcohol } \\
\hline No & 56.1 & 0.51 & 92.3 & 0.53 & 99.2 & 0.36 \\
\hline Yes & 62.6 & & 95.5 & & 100 & \\
\hline \multicolumn{7}{|c|}{ Chemotherapy } \\
\hline No & 57.1 & 0.14 & 91.8 & 0.35 & 100 & 0.11 \\
\hline Yes & 59.6 & & 94.8 & & 98.7 & \\
\hline \multicolumn{7}{|c|}{ Hormone therapy } \\
\hline No & 66.5 & 0.34 & 95.8 & 0.35 & 100 & 0.48 \\
\hline Yes & 55.4 & & 91.3 & & 99.3 & \\
\hline \multicolumn{7}{|l|}{ PTV volume } \\
\hline I & 68.1 & $<0.001$ & 95.2 & 0.24 & 99.4 & 0.91 \\
\hline 2 & 50.2 & & 89.4 & & 99.4 & \\
\hline 3 & 27.3 & & 91 & & 100 & \\
\hline
\end{tabular}

Abbreviations: CG, control group; G, grade; MARA-I, Modulated Accelerated Radiotherapy; PTV, planning target volume; $P$, probability. outcome in $69.8 \%$ of AHF as compared with $71.3 \%$ of patients in the standard fractionation arm. ${ }^{8}$

Furthermore, the 10-year results from START $\mathrm{A}^{8}$ trial showed that normal tissue effects (like breast shrinkage, telangiectasia, and breast edema) were less common in the 39 Gy group and did not differ significantly between 41.6 Gy group and 50 Gy group. ${ }^{8}$

The reason for the differences between AHF impact on late toxicity between our study and the randomized trials could arise from the heterogeneity in the assessment of late toxicity. In fact, in START-A and B, the cosmetic outcomes (presence of breast shrinkage and hardness, change in skin appearance, breast swelling) were defined by patient self-reported assessments. Moreover, in 1,055 of 2,236 patients of START-A and in 923 of 2,215 patients of START-B, change in breast appearance was assessed by photographs taken at baseline, and then at 2 and 5 years with scores on 3-point graded scales. The physician assessments of normal tissue effects in STARTA and B were scored on a 4-point scale (none, a little, quite a bit, or very much). The same authors reported variations between centers in the practice used to complete the yearly reports forms, which could equally have led to underreporting of physician assessment of normal tissue effects. ${ }^{8}$

In our study, normal tissue effects were assessed by two trained physicians (CD, AGM) using the RTOG/EORTC 
Table 7 HRs of GI and G2 late subcutaneous toxicity estimates from Cox proportional-hazards regression models

\begin{tabular}{|c|c|c|c|c|c|c|c|c|}
\hline \multirow[t]{2}{*}{ Variable } & \multirow[t]{2}{*}{ Value } & \multirow{2}{*}{$\begin{array}{l}\text { Late } \\
\text { subcutaneous } \\
\text { toxicity }\end{array}$} & \multicolumn{3}{|c|}{ Univariate analysis $^{\mathbf{a}}$} & \multicolumn{3}{|c|}{ Multivariate analysis $^{a}$} \\
\hline & & & HR & $(95 \% \mathrm{Cl})$ & $P$ & HR & $(95 \% \mathrm{Cl})$ & $P$ \\
\hline \multirow[t]{2}{*}{ Technique } & MARA-I & GI & 2.35 & $(I .6 I-3.4 I)$ & 0.001 & 2.18 & $(1.50-3.18)$ & 0.001 \\
\hline & & $\mathrm{G} 2$ & 3.07 & $(1.11-8.53)$ & 0.031 & 3.01 & $(1.08-8.42)$ & 0.036 \\
\hline \multirow[t]{2}{*}{ Hypertension } & & GI & 0.88 & $(0.64-1.23)$ & 0.458 & & & \\
\hline & & G2 & 1.15 & $(0.52-2.54)$ & 0.725 & & & \\
\hline \multirow[t]{2}{*}{ Diabetes } & & GI & 1.77 & $(1.08-2.90)$ & 0.023 & 1.65 & $(\mathrm{I} .0 \mathrm{I}-2.7 \mathrm{I})$ & 0.047 \\
\hline & & G2 & 2.57 & $(0.87-7.54)$ & 0.086 & & & \\
\hline \multirow[t]{2}{*}{ Tobacco smoking } & & GI & 0.89 & $(0.52-1.53)$ & 0.682 & & & \\
\hline & & G2 & 1.82 & $(0.62-5.33)$ & 0.275 & & & \\
\hline \multirow[t]{2}{*}{ Alcohol } & & GI & 0.82 & $(0.57-1.18)$ & 0.295 & & & \\
\hline & & G2 & 0.79 & $(0.31-1.97)$ & 0.606 & & & \\
\hline \multirow[t]{2}{*}{ Chemotherapy } & & GI & 0.80 & $(0.58-1.10)$ & 0.167 & & & \\
\hline & & $\mathrm{G} 2$ & 0.71 & $(0.32-1.60)$ & 0.414 & & & \\
\hline \multirow[t]{2}{*}{ Hormone therapy } & & GI & 2.34 & $(0.69-8.00)$ & 0.174 & & & \\
\hline & & G2 & 1.20 & $(0.80-\mid .8 I)$ & 0.371 & & & \\
\hline \multirow[t]{2}{*}{ PTV volume } & & GI & 1.14 & $(1.09-1.20)$ & 0.001 & 1.14 & $(1.08-1.20)$ & 0.001 \\
\hline & & $\mathrm{G} 2$ & 1.13 & $(1.01-1.27)$ & 0.027 & 1.14 & $(1.01-1.28)$ & 0.035 \\
\hline
\end{tabular}

Notes: Analysis of 437 patients with complete information. ${ }^{a}$ Covariates to be included in multivariable models were selected with a stepwise backward elimination $(P$ removal $=0.10 ; P$ addition $<0.10$ ) based on likelihood ratio test.

Abbreviations: G, grade; MARA, Modulated Accelerated Radiotherapy.

Scale to evaluate skin and subcutaneous tissue toxicity. We can hypothesize that the palpation of the irradiated breast is more sensitive than photographic evaluation in detecting a mild degree of fibrosis.

Another reason for the different outcomes from our study as compared to the results of the randomized trials could be the fractionation used in our CG (1.8 Gy/fraction), which was lower compared to the standard arm of the randomized trials ( $2 \mathrm{~Gy} /$ fraction). This reduced dose per fraction could have impacted on the incidence of late toxicity in the CG. In addition, the boost technique was different between $\mathrm{CG}$ and MARA-1 trial. In fact, in the CG the boost was delivered with a direct electron beam, while in the MARA-1 trial it was with tangential photon beams. The latter irradiation modality could have probably caused delivery of boost dose to a larger volume. Finally, the finding of a higher rate of fibrosis in MARA-1 patients could be associated to the concomitant boost while CG patients had a sequential boost. In fact, MARA-1 patients received not only a larger dose on PTV1 compared to PTV2 (44 vs 40 Gy) but even a more accelerated fractionation (2.75 vs $2.5 \mathrm{~Gy})$. But comparing the Equivalent Dose in $2 \mathrm{~Gy} /$ fraction $\left(\mathrm{EQD}_{2}\right)$ between the two treatment techniques at the boost site, the $\mathrm{EQD}_{2}$ of MARA-1 and CG groups were 50.6 and 59.4 Gy, respectively. It is therefore difficult to weigh the boost timing as the reason for the recorded differences in terms of late toxicity. Table 3 shows a clear imbalance in terms of adjuvant pharmacological treatments. The percentage of patients receiving chemotherapy was close to double in the
CG compared to the MARA- 1 patients ( $64.6 \%$ vs $33.1 \%$ ). This figure may have played a role in the different late toxicity rates recorded in the two groups. However, it should be emphasized that the significant impact of RT was confirmed on multivariate analysis, in which both chemotherapy and hormone therapy were included.

Despite the higher rate of late subcutaneous toxicity in the MARA-1 group, the significant differences were limited only to the lower grades (G1-G2), whereas the absence of G3-G4 could be attributed to the IMRT technique. In fact, several studies have confirmed the role of IMRT in BC in terms of improvement of dosimetric parameters, higher homogeneity in dose distribution, and reduced severity of acute toxicity. ${ }^{15,16}$ Two retrospective cohort studies have reported late toxicity, both with positive results. ${ }^{17,18}$ The study by Harsolia et al, ${ }^{17}$ showed a significant difference between IMRT and conventional wedge-based RT, and was in favor of IMRT for chronic (G2 or greater) breast edema ( $3 \%$ vs $30 \% ; P=0.007$ ) with no differences in terms of hyperpigmentation or fibrosis. In the study of McDonald et al, ${ }^{18}$ the authors reported a trend toward a reduced incidence of lymphedema in patients treated by IMRT compared to conventional treatment ( $0 \%$ vs $4 \%$; $P=0.06$ ). In contrast, the 10 -year results of the Canadian randomized trial comparing IMRT with traditional RT did not show significantly different results in terms of late toxicity. The authors concluded that IMRT cannot be recommended in all $\mathrm{BC}$ patients treated with BCT. ${ }^{19}$

Our study also showed a significant difference in terms of 5-year locoregional control $(96.7 \%$ and $100 \%$ in CG and 
MARA-1 groups, respectively; $P=0.02$ ). However, this result should be considered with caution considering the different inclusion criteria between the two groups. In CG group, even patients with $>3$ metastatic axillary nodes, in premenopausal status, with close margins, and pT4 tumors were enrolled. In fact, Table 2 shows a clear imbalance of prognostic factors in favor of MARA-1 group in terms of tumor grading and nodal stage. For these reasons, we did not compare the differences in terms of disease-free and overall survival.

\section{Conclusion}

Our study confirmed the feasibility of an AHF treatment, especially using IMRT technique. Assessing late toxicity by clinical examination, a higher incidence of subcutaneous side effects was recorded in patients undergoing AHF. However, this increase was limited to G1-G2 toxicity. Therefore, the results of our study are not enough to question the safety of hypofractionated regimens in this setting, which have been tested in large randomized controlled trials and have become the clinical standard in many centers. However, we believe that in patients with multiple risk factors for late toxicity (larger PTV volume, diabetes, tobacco smoking), caution should be taken during and after treatment also considering the demonstrated correlation between acute and late effects. ${ }^{19}$ Further trials on this topic will be useful to identify more precisely the patients who deserve this particular attention. The results from some trials ${ }^{20,21}$ that completed enrollment some years ago and pending publication could clarify some unanswered questions regarding this issue.

\section{Dedication}

This paper is dedicated to our colleague Cinzia Digesù (19712015) who passed away when the study was under development and whose contribution to this trial was invaluable.

\section{Disclosure}

The authors report no conflicts of interest in this work.

\section{References}

1. Poortmans P. Evidence-based radiation oncology. Breast cancer. Radiother Oncol. 2007;84:84-101.

2. Clarke M, Collins R, Darby S, et al. Effects of radiotherapy and of differences in the extent of surgery for early breast cancer on local recurrence and 15-year survival: an overview of the randomized trials. Lancet. 2005;366:2087-2106.

3. Fisher B, Anderson S, Redmond CK, Wolmark N, Wickerham DL, Cronin WM. Reanalysis and results after 12 years of follow-up in a randomized clinical trial comparing total mastectomy with lumpectomy with or without irradiation in the treatment of breast cancer. $N$ Engl J Med. 1995;333(22):1456-1461.
4. Xs Q, White J, Xa L. Is alpha/beta for breast cancer really low? Radiother Oncol. 2011;100:282-288.

5. Evans PM, Donovan EM, Partridge M, et al. The delivery of intensity modulated radiotherapy to the breast using multiple static fields. Radiother Oncol. 2000;57(1):79-89.

6. Fletcher GH. Hypofractionation: lessons from complications. Radiother Oncol. 1991;20(1):10-15.

7. Owen JR, Ashton A, Bliss JM, et al. Effect of radiotherapy fraction size on tumour control in patients with early-stage breast cancer after local tumour excision: long-term results of a randomised trial. Lancet Oncol. 2006;7(6):467-471.

8. Haviland JS, Owen JR, Dewar JA, et al. The UK Standardisation of Breast Radiotherapy (START) trials of radiotherapy hypofractionation for treatment of early breast cancer: 10-year follow-up results of two randomised controlled trials. Lancet Oncol. 2013;14:1086-1094.

9. Whelan TJ, Pignol JP, Levine MN, et al. Long-term results of hypofractionated radiation therapy for breast cancer. $N$ Engl $J$ Med. 2010;362(6):513-520.

10. Smith BD, Bentzen SM, Correa CR, et al. Fractionation for whole breast irradiation: an American Society for Radiation Oncology (ASTRO) evidence-based guideline. Int J Radiat Oncol Biol Phys. 2011;81(1): $59-68$.

11. Jagsi R, Griffith KA, Boike TP, et al. Differences in the acute toxic effects of breast radiotherapy by fractionation schedule: comparative analysis of physician-assessed and patient-reported outcomes in a large multicenter cohort. JAMA Oncol, published online. 2015.

12. Morganti AG, Cilla S, Valentini V, et al. Phase I-II studies on accelerated IMRT in breast carcinoma: technical comparison and acute toxicity in 332 patients. Radiother Oncol. 2009;90(1):86-92.

13. Cox JD, Stetz J, Pajak TF. Toxicity criteria of the Radiation Therapy Oncology Group (RTOG) and the European Organization for Research and Treatment of Cancer (EORTC). Int J Radiat Oncol Biol Phys. 1995;31(5):1341-1346.

14. Yarnold J, Ashton A, Bliss J, et al. Fractionation sensitivity and dose response of late adverse effects in the breast after radiotherapy for early breast cancer: long-term results of a randomised trial. Radiother Oncol. 2005;75(1):9-17.

15. Buwenge M, Cammelli S, Ammendolia I, et al. Intensity modulated radiation therapy for breast cancer: current perspectives. Breast Cancer. 2017;9:121-126.

16. Morganti AG, Cilla S, de Gaetano A, et al. Forward planned intensity modulated radiotherapy (IMRT) for whole breast postoperative radiotherapy. Is it useful? When? J Appl Clin Med Phys. 2011;12(2):3451-222.

17. Harsolia A, Kestin L, Grills I, et al. Intensity-modulated radiotherapy results in significant decrease in clinical toxicities compared with conventional wedge-based breast radiotherapy. Int J Radiat Oncol Biol Phys. 2007;68(5):1375-1380.

18. Mcdonald MW, Godette KD, Butker EK, Davis LW, Johnstone PA. Long-term outcomes of IMRT for breast cancer: a single-institution cohort analysis. Int J Radiat Oncol Biol Phys. 2008;72(4):1031-1040.

19. Pignol JP, Truong P, Rakovitch E, Sattler MG, Whelan TJ, Olivotto IA. Ten years results of the Canadian breast intensity modulated radiation therapy (IMRT) randomized controlled trial. Radiother Oncol. 2016;121(3):414-419.

20. Yarnold J. Radiation therapy in treating women who have undergone breast conservation surgery and systemic therapy for early breast cancer. Available from: http://clinicaltrials.gov/show/NCT00818051. NLM identifier NCT00818051. Accessed February 26, 2018.

21. Vicini F. Higher per daily treatment-dose radiation therapy or standard per daily treatment radiation therapy in treating patients with earlystage breast cancer that was removed by surgery. Available from: http:// clinicaltrials.gov/show/NCT01349322. NLM identifier NCT01349322. Accessed February 26, 2018 
Breast Cancer - Targets and Therapy is an international, peerreviewed open access journal focusing on breast cancer research, identification of therapeutic targets and the optimal use of preventative and integrated treatment interventions to achieve improved outcomes, enhanced survival and quality of life for the cancer patient
The manuscript management system is completely online and includes a very quick and fair peer-review system, which is all easy to use. Visit http://www.dovepress.com/testimonials.php to read real quotes from published authors.

Submit your manuscript here: https:/www.dovepress.com/breast-cancer---targets-and-therapy-journal 